\title{
JAUES
}

Journal of Al-Azhar University Engineering Sector

Vol.15, No. 55, April, 2020, 594-603

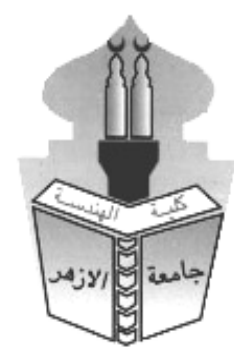

\section{NUMERICAL ANALYSIS OF ANCHORED SHEET PILE WALLS}

\author{
Moamen E. Abd EI Raouf \\ Civil Engineering Department, Faculty of Engineering, Al- Azhar University, Qena, Egypt. \\ E-Mail: moamenabdelmontaleb@azhar.edu.eg
} ABSTRACT

\begin{abstract}
Anchored sheet pile walls are used to restrain excavation when the depth of the excavation exceeds about $6 \mathrm{~m}$. In this paper, the influence of some parameters on anchored sheet pile walls was studied. The parameters are: anchor inclination with the horizontal ground, the number of anchors (one -row, or more), the cohesion of soil, and angle of internal friction of the backfill soil. The previous parameters affect soil behavior, wall bending moments, and wall displacement. Numerical analysis of the anchored sheet pile walls was implemented using a finite element program GEO5. The results of the analysis indicated that the optimum angle of anchor inclination is 25 degrees to reduce the horizontal displacement at the top of the wall and maximum bending moment. Variation of the angle of internal friction has a significant effect on the wall. As the friction angle increases, the maximum displacement and the internal forces decrease. As the cohesion of soil increases, the maximum bending moment, shear force, and wall displacement decreases. Increasing the number of anchors decreases the maximum bending moment, wall displacement, and increases the maximum shear force.
\end{abstract}

\section{KEYWORDS: Anchored Sheet Pile Wall, Numerical Analysis, Cohesion, Angle Of Internal Friction.}

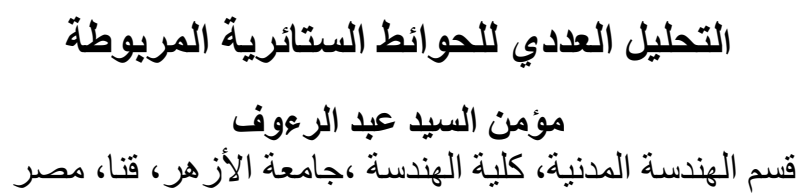

E-mail: moamenabdelmontaleb@azhar.edu.eg البريد الإليكترونى للباحث:

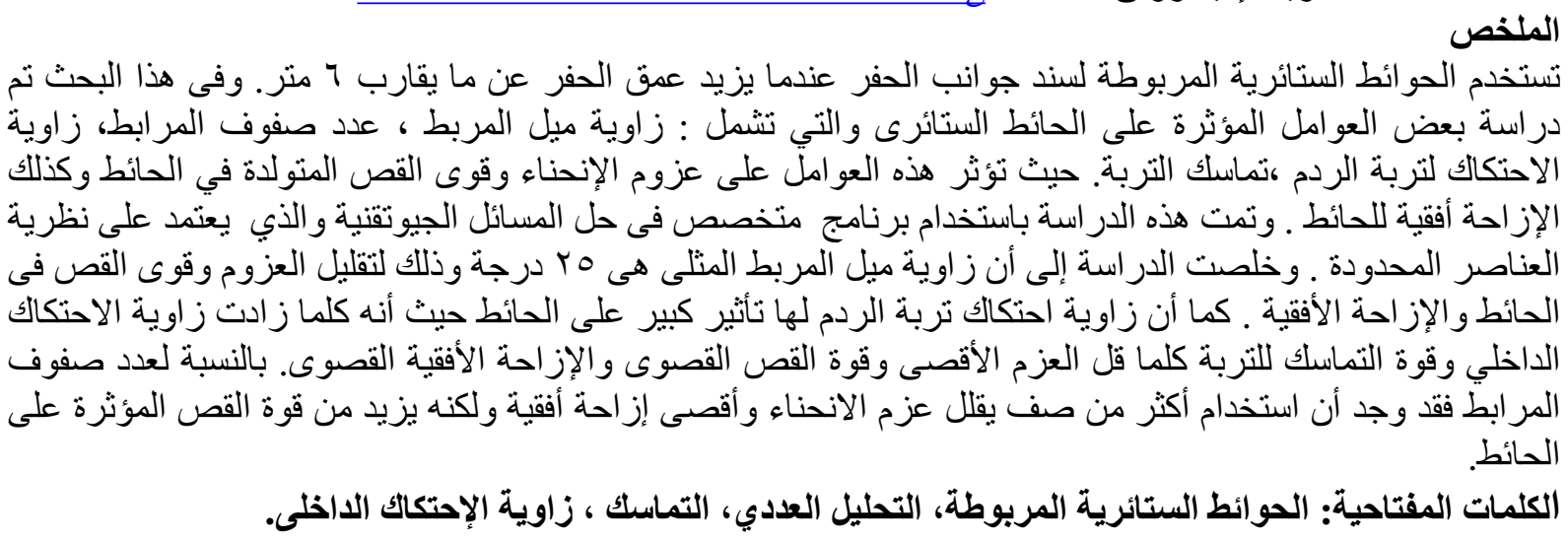

\section{INTRODUCTION}

Cantilever sheet pile walls are a traditional solution to cover the problems of the deep excavation adjacent to buildings, this solution characterized by simplicity and reliability. In 
recent decades till now, the cantilever sheet pile walls are still broadly used. Various types of materials can be used as a sheet pile walls: timber, steel or reinforced concrete. Cantilever sheet pile walls used to restrain excavation when the depth of the excavation is small. When the depth of the excavation exceeds about $6 \mathrm{~m}$, the anchored sheet pile walls are used $[1,2]$. The anchored sheet pile walls are designed by two main methods: (a) the free earth support method and (b) the fixed earth support method.

The usage of anchors results in reducing the penetration depth and decrease the value of the bending moment, shear force and wall deflection, therefore, reduces the cross-section of the wall and the reinforcement (in case of concrete sheet pile walls) as shown in figure (1).

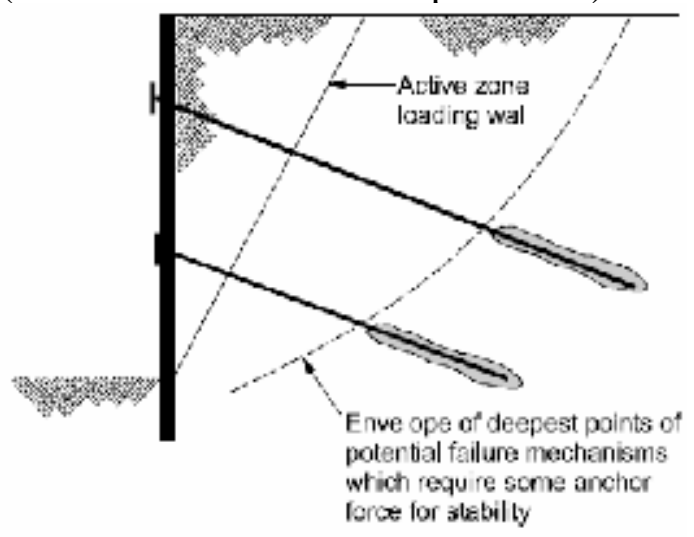

Figure (1) Influence of ground anchors on wall stability (after Sabatini et.al., 1999)

Design of anchored sheet pile wall depends on many factors like the height of excavation, surcharge loads, the kind of structure (temporary or permanent), and the level of groundwater table [3].The analysis and design of cantilever sheet pile walls and anchored sheet pile walls can be carried out utilizing a numerical model or traditional methods that depend on the limit equilibrium approach. Many researchers studied the safety conditions, soil deformation, lateral earth pressure distribution and stress-strain analysis for cantilever sheet pile walls and anchored sheet pile walls using the finite element method $[4,5,6,7,8,9,10,11,12,13]$. Tang et al. [14] used a finite element model based on field data to investigate the lateral earth pressure distribution on sheet pile walls and provide the guidelines recommendations to design the sheet pile walls. Ömer Bilgin [15] studied the behavior of single-level anchored sheet pile walls using conventional and numerical methods and analysed the changes in the bending moment of the wall, anchor force, and lateral earth pressure distribution.

In the present paper, the influence of some parameters were studied such as: anchor inclination with the horizontal ground, the number of anchors (one -row, or more), the cohesion of soil, angle of internal friction of the backfill soil. These parameters affect soil behavior, wall bending moments, wall displacement, ground settlement, and anchor forces. The numerical analysis of anchored sheet pile walls was implemented via a commercial finite element program GEO5.

\section{Limit Equilibrium Analysis}

Design and analysis of cantilever sheet pile walls and anchored sheet pile walls by the classical method depends on Rankine's theory to determine the earth pressure acting on sheet pile walls. The classical methods based on the limit state equilibrium take into account the internal stability and external stability of the sheet pile walls. The traditional methods are associated with some insufficiency. For instance, the classical methods fail to study the soilstructure interaction, defamation, and construction stages. The conventional analytical analysis based on the limit state equilibrium can be performed using manual calculation or software programs. The program can solve the geotechnical problems using two methods. The finite element method, and classical methods by GEO 5 sheeting design program.

\section{NUMERICAL MODEL}

GEO5 is a program used to perform stability analysis and determination of the deformation and stresses for many geotechnical problems. GEO5 program contains two options to solve 
geotechnical problems: classical methods and finite element method. The program works as follows: first, the structure is solved analytically to calculate the internal forces then it is transferred to the finite element program to verify the stress and deformation.

The employment of the numerical model provides more details for the behavior of both soil and structure and design outputs. Also, the numerical model permits the designer to study more variables during the design process.

\section{MODELING AND PARAMETERS}

Modeling the sheet piles walls in GEO5 program involves many parameters such as parameters of soil, pile, and loads.

The geometry used in this analysis is an anchored sheet pile walls of $10 \mathrm{~m}$ height. The retained depth above the dredge level is $5.5 \mathrm{~m}$ and the embedment depth $4.5 \mathrm{~m}$. The studied sheet pile wall is a steel sheet pile (VL-503k).

The properties of anchors, soil, and sheet pile wall (VL-503k) are shown in tables (1), (2) and (3) respectively.

Table (1) The anchor properties

\begin{tabular}{|l|l|}
\hline Anchor length & $20 \mathrm{~m}$ \\
\hline Anchor spacing & $1.2 \mathrm{~m}$ \\
\hline Anchor diameter & $10 \mathrm{~mm}$ \\
\hline
\end{tabular}

Table (2) Soil properties

\begin{tabular}{|l|c|}
\hline Cohesion (kpa) & 1 \\
\hline Modulus of elasticity, E (Mpa) & 12 \\
\hline Unload Modulus of elasticity, $\mathbf{E}_{\mathrm{ur}}(\mathrm{Mpa})$ & 21 \\
\hline Unit weight of soil, $\mathrm{kN} / \mathrm{m}^{3}$ & 19 \\
\hline Poisson's ratio & 0.3 \\
\hline Friction angle & 30 degrees \\
\hline Saturated unit weight of soil, $\mathrm{kN} / \mathrm{m}^{3}$ & 21 \\
\hline
\end{tabular}

Table (3) Properties of sheet pile wall (VL- 503k)

\begin{tabular}{|l|l|}
\hline Area & $156.4\left(\mathrm{~cm}^{2} / \mathrm{m}\right)$ \\
\hline Moment of inertia & $22054\left(\mathrm{~cm}^{4} / \mathrm{m}\right)$ \\
\hline Weight & $122.8 \mathrm{~kg} / \mathrm{m}^{2}$ \\
\hline Thickness & $10 \mathrm{~mm}$ \\
\hline Width & $400 \mathrm{~mm}$ \\
\hline
\end{tabular}

\section{FINITE ELEMENT ANALYSIS}

The modified Mohr - Coulomb constitutive model for soils was used to simulate the behavior of the anchored sheet pile walls. The mesh generation result was as follows: the number of nodes 5186 and the number of elements 3030 (region 2006, beam 256, interface 768) as shown in figure (2). The investigated results include maximum bending moment, shear force, and horizontal displacement.

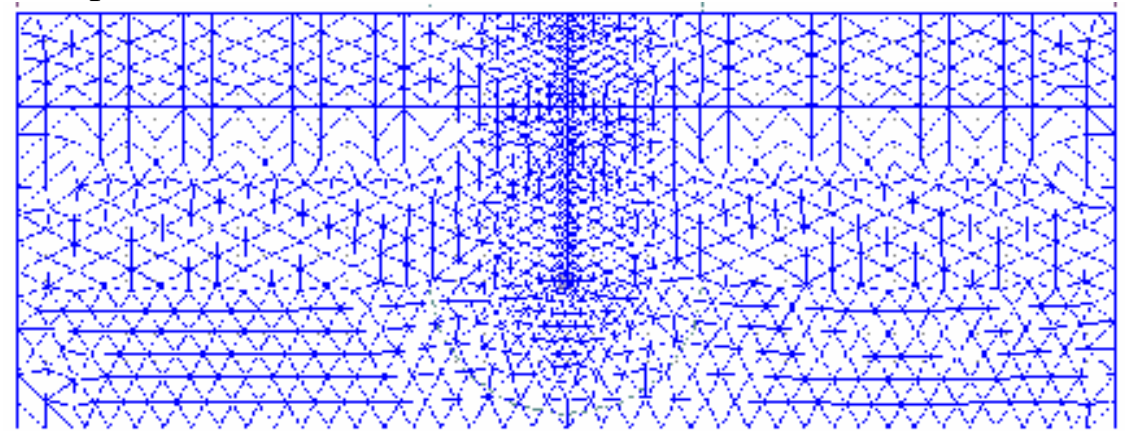

Figure (2) Finite Element Mesh 


\section{RESULTS AND DISCUSSION}

In this section, the effect of input data on the output results will be studied. The input data studied in this analysis are the anchor inclination, the number of anchors, angle of internal friction of backfill soil, and cohesion of soil. The numerical method results can be summarized as follow:

\subsection{Anchor Inclination}

In this analysis, anchor rods with inclination 0,10,15,20,25,30, 35 and 45 degrees were studied. From the finite element results, it was noticed that the maximum horizontal displacement has occurred at the top of wall as shown in figure (3).
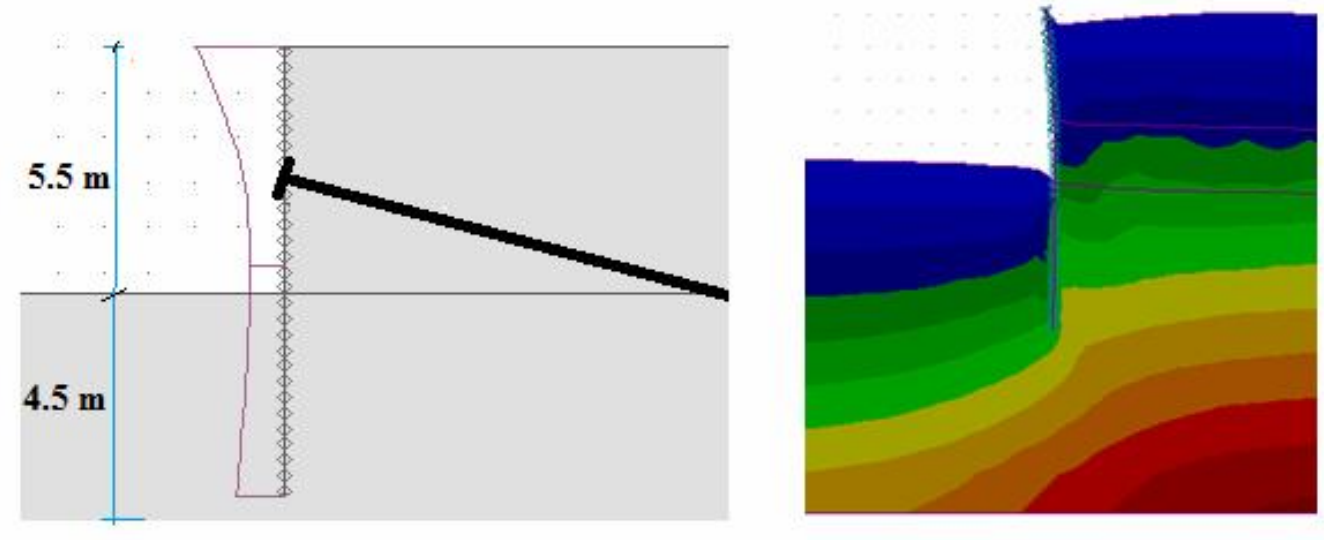

Figure (3) The wall deformation

Figure (4) shown the relation between the maximum horizontal displacement and the anchor inclination angle. The results indicated the minimum horizontal displacement is for the inclination angle equals 25 degrees. When the angle of inclination exceeds than 25 degrees, the maximum horizontal displacement increases, as the anchor inclination angle increases.

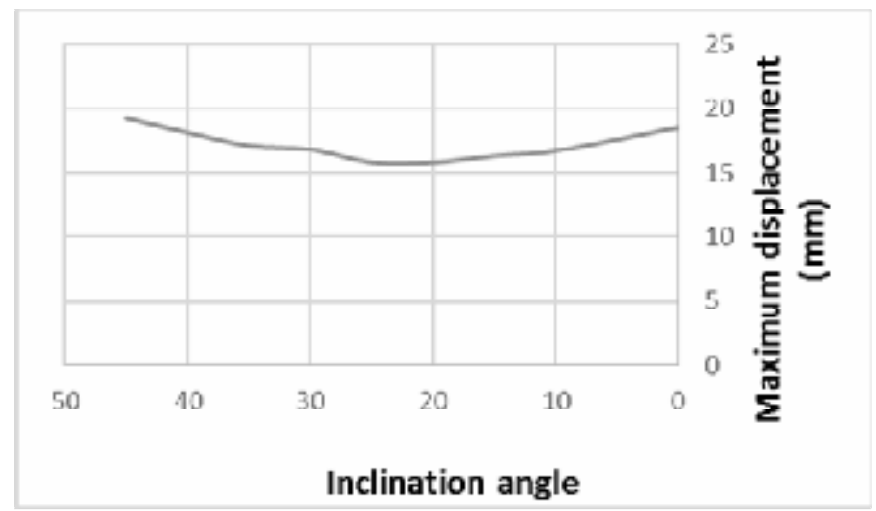

Figure (4) The relation between the maximum displacement and the anchor inclination angle

The results also showed that, the maximum bending moment decreases, as the anchor inclination increases, except when the angle of inclination is zer o. The maximum bending moment occurs when the angle of inclination equals 10 degrees as shown in figure (5). 


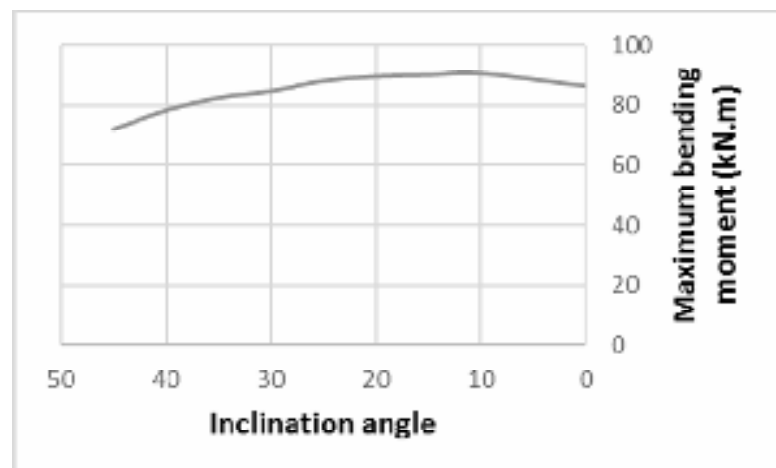

Figure (5) The relation between the maximum bending moment and the anchor inclination

Figure (6) indicated that the maximum shear force decreases, as the anchor inclination increases, except when the angle of inclination is zero. The value of the maximum shear force when the angle of inclination equals to 10 degrees.

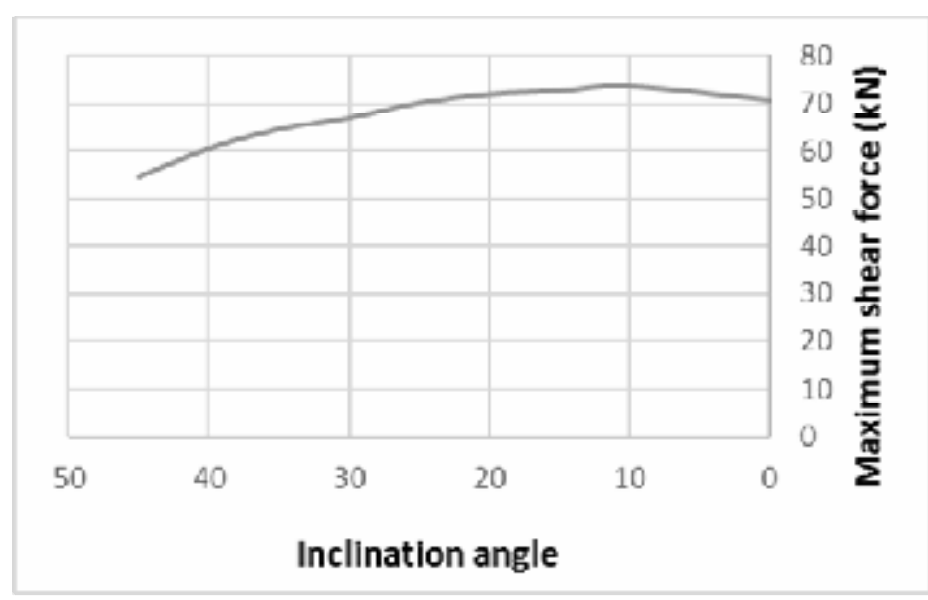

Figure (6) The relation between the maximum shear force and the anchor inclination angle

\subsection{Influence of the Number of Anchors}

In this analysis, a case of two and three-rows were studied to compare with the case of a single anchored sheet pile walls. It's common to put the first anchor at the top of the wall on the depth equals $(0.2 \mathrm{H})$ to control the top movement of the wall (where $\mathrm{H}$ is the retained depth above the dredge level) [2]. The geometry used in this analysis is an anchored sheet pile walls of $16 \mathrm{~m}$ height. The retained depth above the dredge level is $8 \mathrm{~m}$ and the embedment depth $8 \mathrm{~m}$. The anchor properties were shown in table (4).

\begin{tabular}{|l|l|}
\multicolumn{1}{|c|}{ Table (4) The anchor properties } \\
\hline Total anchor length & $20 \mathrm{~m}$ \\
\hline Anchor spacing & $1.2 \mathrm{~m}$ \\
\hline Anchor diameter & $10 \mathrm{~mm}$ \\
\hline Anchor rows & 1 \\
\hline Anchor inclination & $15^{\circ}$ \\
\hline Depth of the first anchor from the ground surface & $2 \mathrm{~m}$ \\
\hline The vertical distance between anchors & $2 \mathrm{~m}$ \\
\hline
\end{tabular}

The results of the analysis were shown in table (5).

Table (5) Comparison between the results for one -row, two-rows and three - rows of anchors

\begin{tabular}{|l|l|l|l|}
\hline $\begin{array}{l}\text { No. of } \\
\text { anchors }\end{array}$ & $\begin{array}{l}\text { Maximum bending } \\
\text { moment }(\mathbf{k N . m})\end{array}$ & $\begin{array}{l}\text { Maximum Shear } \\
\text { force }(\mathrm{kN})\end{array}$ & $\begin{array}{l}\text { Maximum } \\
\text { displacement }(\mathbf{m m})\end{array}$ \\
\hline 1 & 94.35 & 74.63 & 14 \\
\hline 2 & 73.23 & 88.67 & 4.7 \\
\hline 3 & 60.58 & 90.14 & 3.7 \\
\hline
\end{tabular}


The results indicated that using two-rows anchors reducing the maximum bending moment about $22 \%$ and the maximum displacement decreased to value about $66.4 \%$, whilst the maximum shear force increased to a value of about $16 \%$. Use three-rows of anchors led to decreasing the maximum bending moment of about $36 \%$. Also, the maximum displacement decreased to value about $73.5 \%$ of the maximum displacement in the case of using one-row of anchors. The maximum shear force increased also to a value of about $17.2 \%$ as shown in figures $7 \& 8$.

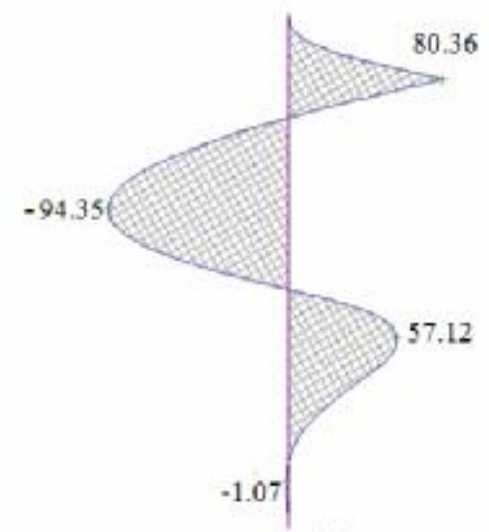

(a)

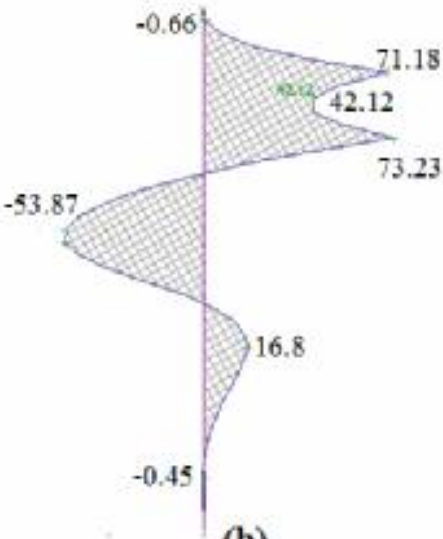

(b)

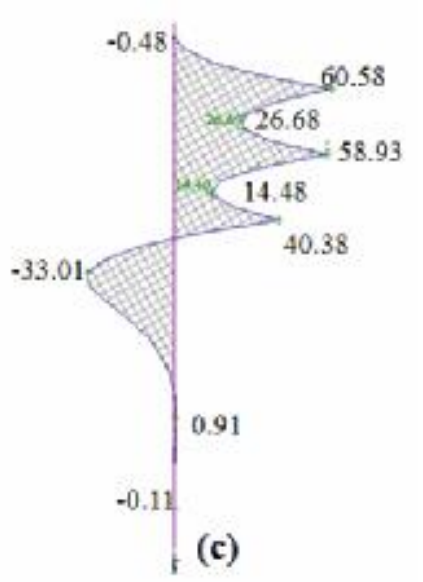

(c)

Figure (7) Comparison between bending moment diagrams for :( a) one-row of anchors, (b) two-rows of anchors, and (c) three-rows of anchors

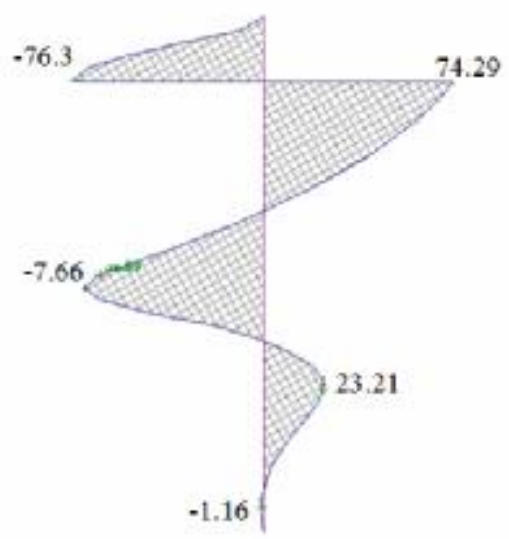

(a)

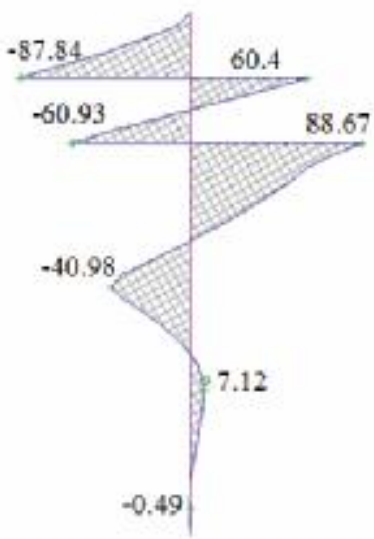

(b)

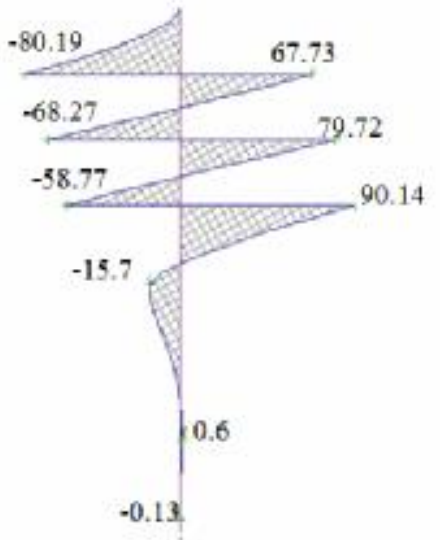

(c)

Figure (8) Comparison between shear force diagrams for :( a) one-row of anchors, (b) two-rows of anchors, and (c) three-rows of anchors

\subsubsection{The optimum number of anchors rows}

Use two- rows of anchors reduces the maximum displacement by a significant value and reduces the maximum bending moment about $22 \%$. Using three-rows of anchors reduces the maximum bending moment of about $36 \%$ and reduces the maximum displacement by a little value in comparison with the use of two-rows anchors. So, it's recommended to use tow-rows of anchors whereas the use of thee-rows of anchors is more expansive and needs more construction stages, which means increasing the time and the cost of construction and increase the shear force.

\subsection{Effect Backfill Friction Angle}

In this section, the effect of varying friction angle on the output value was studied. Four types of sandy soil as follows: loose sand $\left(\phi=30^{\circ}, \gamma=17 \mathrm{kN} / \mathrm{m}^{3}\right)$, medium dense sand $\left(\phi=35^{\circ}\right.$, 
$\left.\gamma=19 \mathrm{kN} / \mathrm{m}^{3}\right)$, dense sand $\left(\phi=40^{\circ}, \gamma=2.1 \mathrm{kN} / \mathrm{m}^{3}\right)$ and very dense sand $\left(\phi=45^{\circ}, \gamma=2.2\right.$ $\mathrm{kN} / \mathrm{m}^{3}$ ). Figures from (9) to (11) show the output value results in varying the angle of internal friction.

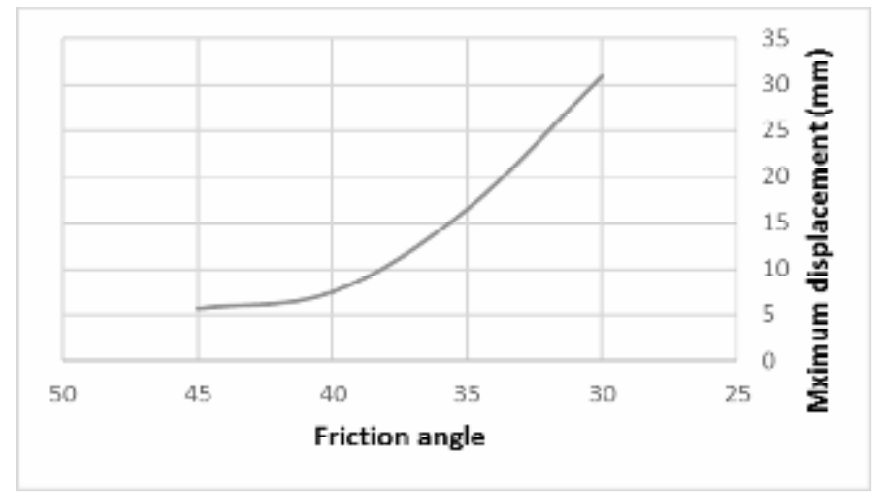

Figure (9) Effect the varying of friction angle on maximum displacement

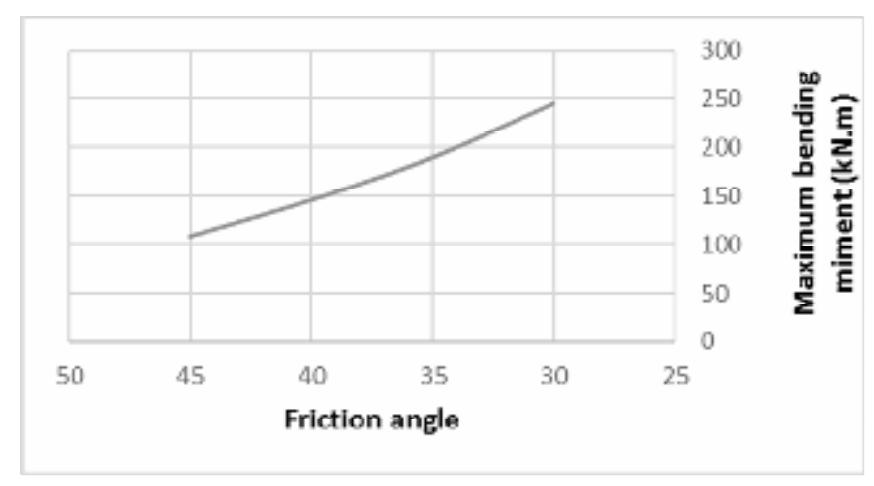

Figure (10) Effect the varying of friction angle on maximum bending moment

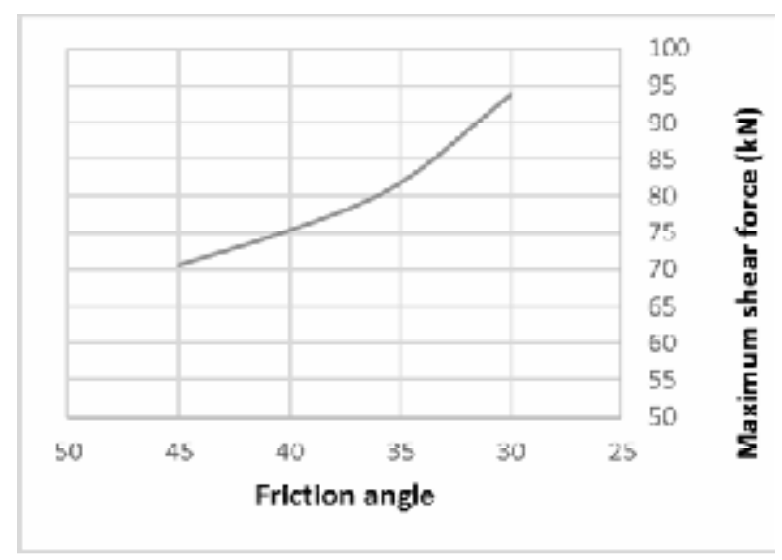

Figure (11) Effect the varying of friction angle on maximum shear force

The results indicated that the wall displacement decreases, as the friction angle is increased. Also, the maximum bending moment and maximum shear force decrease, as the angle of the internal friction angle is increases.

\subsection{Effect the soil cohesion}

In this section, the effect of varying of soil cohesion on the bending moment, shear force, horizontal displacement was considered. Three types of clayey soil were taken into account in this analysis: soft clay, medium clay, and stiff clay. The cohesion of soil is ranged from 10 $\mathrm{kN} / \mathrm{m}^{2}$ to $100 \mathrm{kN} / \mathrm{m}^{2}$ according to its type as shown in table (6). 
Table (6) The soil properties

\begin{tabular}{|l|l|l|l|}
\hline Soil type & $\begin{array}{l}\text { Modulus of } \\
\text { elasticity (Mpa) }\end{array}$ & Cohesion (kpa) & $\begin{array}{l}\text { Friction angle } \\
\text { degree }\end{array}$ \\
\hline Soft clay & 5 & 10,20 & 0 \\
\hline Medium clay & 10 & $\mathbf{3 0 , 4 0 , 5 0}$ & 0 \\
\hline Stiff clay & 15 & $\mathbf{8 0 , 9 0 , 1 0 0}$ & 0 \\
\hline
\end{tabular}

The results of the analysis were shown in figures from (12) to (14).

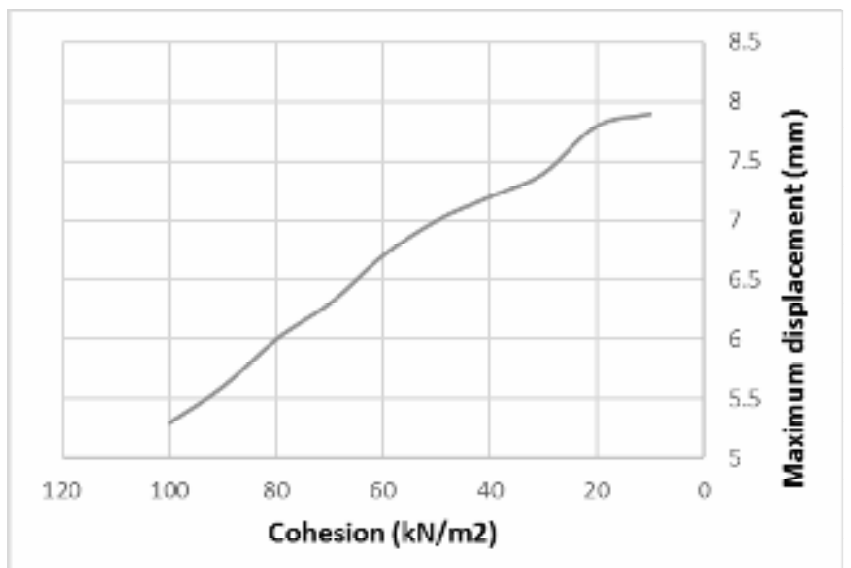

Figure (12) The relation between the maximum displacement and the soil cohesion

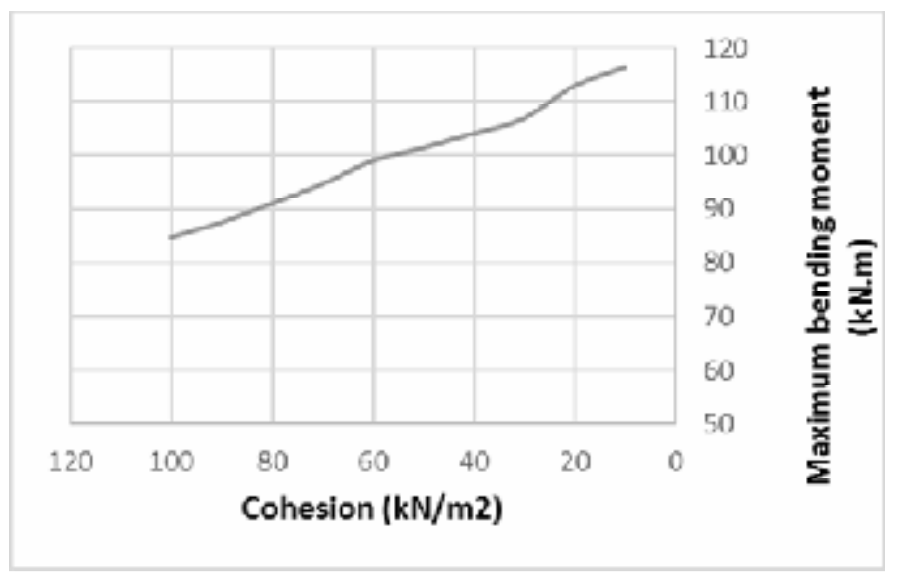

Figure (13) The relation between the maximum bending moment and the soil cohesion

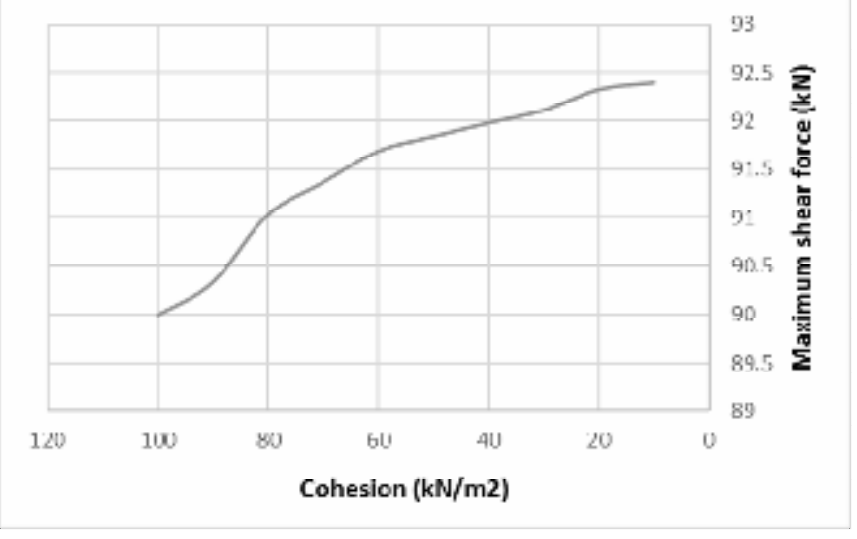

Figure (14) The relation between the maximum shear force and the soil cohesion. 
The results show that, the maximum displacement, maximum bending moment, and maximum shear force decreases, as the cohesion of soil decreases. This effect is due to the increase of passive earth pressure as a result of an increase in soil cohesion. As well as the active earth pressure decreases by the increase of the soil cohesion.

\section{CONCLUSION AND RECOMMENDATION}

- The optimum angle of anchor inclination is 25 degrees to reduce the horizontal displacement at the top of the wall, the maximum bending moment, and the maximum shear force.

- The variation of angle of internal friction has a significant effect on the wall deformation. The maximum displacement of the wall decreases, as the friction angle increases. Also, the maximum bending moment and maximum shear force decrease, as the friction angle increases.

- As the cohesion of soil increases, the maximum displacement decreases. Also, the maximum bending moment and maximum shear force decrease, as the cohesion of soil increases.

- Increasing the number of anchors decreases the maximum bending moment and maximum displacement. Also, increasing the number of anchors increases the maximum shear force.

- For deep excavation, it's recommended to use tow-rows of anchors to reduces the maximum displacement and maximum bending moment which may be practical economical for wall of height $8 \mathrm{~m}$.

\section{REFERENCES}

1. P.J. Sabatini, D.G. Pass, R.C. Bachus, (1999) " Geotechnical Engineering Circular NO. 4,Ground Anchors and Anchored Systems"Federal Highway administration. Publication No. FHWA-IF-99-015.

2. Das B.M.,(2010) "Principles of Foundation Engineering"Cengage Learning, CT, USA.

3. V.N.S, Murthy.(2003)."Geotechnical engineering: principles and practices of soil mechanics and foundation engineering". Marcel Dekker,inc. New York.

4. Bahrami, M., Khodakarami, M. I. \& Haddad, A. (2018)."3D numerical investigation of the effect of wall penetration depth on excavations behavior in sand" Computers and Geotechnics, 98, 82-92, doi: 10.1016/j.compgeo.2018.02.009.

5. Cherubini, C. (2000). "Probabilistic approach to the design of anchored sheet pile walls". Computers and Geotechnics, 26, 309-330.

6. Dina A. Emarah 'Safwat A. Seleem, (2018)"A numerical study of anchored sheet piles subjected to different types of sandy soils backfill". HBRC Journal,vol.14, no.3,p. 422-30.

7. Finno, R.J., Blackburn, J.T. \& Roboski, J.F. (2007)."Three-dimensional effects for supported excavations in clay". Journal of Geotechnical and Geo environmental Engineering, 133, 30-6, doi:10.1061/(ASCE)1090-0241(2007)133:1(30).

8. GuhaRay, A. \& Baidya, D. K. (2015). "Reliability-based analysis of cantilever sheet pile walls backfilled with different soil types using the finite-element approach". International Journal of Geomechanics,15,06015001, doi: 10.1061/(ASCE)GM.19435622.0000475.

9. Grande, L., Soreide, O.K., Tefera, T.H. (2002). " Large scale model testing on the moment distribution and deformation behavior of a sheet pile wall", 2nd International Conference on Soil Structure Interaction in Urban Civil Engineering, Zurich, Switzerland, pp. 389-394.

10. Kumar, N., Dey, A. (2014)."Behavior of Rigid Cantilever Sheet Pile Walls: Numerical and Finite Element Analysis", Indian Geotechnical Conference, Netherlands, pp. 1820.

11. Sheng, D., Sun, D. A. \& Matsuoka, H. (2006). "Cantilever sheet-pile wall modelled by frictional contact". Soils and Foundations, 46, 29-37, doi:10.3208/sandf.46.29.

12. Hou,Y. M., Wang, J. H. \& Zhang, L. L.(2009). "Finite-element modeling of a complex deep excavation in Shanghai". Acta Geotechnica, 4, 7-16, doi: 10.1007/s11440-0080062-3. 
13. Tan, H., Jiao,Z.\& Chen,J.(2018). "Field testing and numerical analysis on performance of anchored sheet pile quay wall with separate pile-supported platform. Marine Structures", 58, 382-398, doi: 10.1016/j.marstruc.2017.12.006.

14. Tang, L.,Cong, S., Xing, W., Ling, X., Geng, L., Nie, Z., \& Gan, F. (2018). "Finite element analysis of lateral earth pressure on sheet pile walls". Engineering Geology, 244, 146-158.

15. Ömer Bilgin.,(2012) "Lateral Earth Pressure Coefficients for Anchored Sheet Pile Walls" International Journal of Geomechanics ASCE, Vol. 12, Issue 5. 